\title{
Evolução não linear dos produtos para preparo de café: métodos de infusão
}

André Carvalho Mol Silva;

Sebastiana Luiza Bragança Lana;

Marcelina das Graças de Almeida

resumo:

Este artigo destaca o café como produto relevante do mercado de consumo mundial, com destaque produtivo em Minas Gerais. A partir de levantamento bibliográfico, o objetivo desta comunicação é apresentar como os produtos usados no preparo do café coexistem ao longo do tempo, não seguindo um padrão de evolução linear no qual um produto novo substitui seu antecessor. No estudo de caso é apresentado o processo de infusão e seis diferentes métodos relacionados, cada um com dispositivos específicos de preparo, sendo um campo aberto para inovação através do design, ainda pouco explorado no Brasil. Observa-se que no segmento analisado as inovações e invenções, em geral, não inutilizam os produtos antigos, pois as formas de se consumir o café são variadas de tal forma, que qualquer alteração nos processos ou pequenas mudanças nos produtos proporcionam novos resultados, e assim os novos produtos acabam se somando aos tradicionais, e não os substituindo.

palavras-chave:

Produtos; café; design; inovação 


\section{Introdução}

Com produção de mais de 10 milhões de toneladas e consumo de mais de 9,7 milhões de toneladas ${ }^{1}$ em 2018, o café movimenta a economia de muitos países, com destaque para o Brasil, com a maior produção mundial e o segundo país em consumo (MAPA, 2018). O desempenho mineiro neste cenário é tão relevante que, caso o estado de Minas Gerais fosse considerado separadamente do Brasil, seria o maior produtor mundial de café, seguido do Vietnã e só então, apareceria o Brasil em terceiro ${ }^{2}$.

A destacada produção do café no Estado tem forte impacto econômico regional e nacional, além de tornar o produto culturalmente relevante no cotidiano do povo mineiro. Icônico como o pão de queijo, a goiabada, o queijo e a cachaça, o café está presente nas casas, no comércio e no imaginário da população. Contudo, como acontece com outros fatores culturais, os hábitos ligados ao café também sofrem influência das conexões proporcionadas pela globalização, seja passando por trocas, inovações e releituras nos processos de preparo e consumo, seja pela curiosidade e acesso a grãos diferenciados e maior informação sobre seus produtores e regiões produtoras (ICO, 2016 e OLIVEIRA, 2019), além de conhecer novos produtos e processos para preparo da bebida.

Café, hoje, não é mais uma bebida amarga e necessariamente escura, superconcentrada. Beber café hoje é cool, tem a cara e o jeito dos jovens. O público jovem, além de consumidor, tem encontrado no café um novo nicho, a possibilidade de desenvolver carreiras ligadas ao produto. [...] A antiga receita da geração dos nossos avós voltou de maneira reformulada. O café filtrado cresce e ganha espaço, mas seguindo o conceito monodose - preparado na AeroPress ${ }^{\circledR}$, no filtro de papel, ou em sachês ou cápsulas. (HERSZKOWICZ, 2014, p. 44)

Como um produto que percorre os diferentes setores da economia, o café está presente também na indústria: no processamento e transformação dos grãos e na manufatura de produtos de preparo, conservação e consumo; e nos serviços: ocupando espaços privilegiados nas redes de atacado e varejo, em lojas especializadas, em lojas de produtos naturais e em cafeterias (ABIC, 2017), além de estar disponível em praticamente todos os restaurantes, lanchonetes e padarias.

O cenário que se apresenta atualmente é de renovação do público e do comportamento de consumo, que após a revolução proporcionada pelas cápsulas, voltou seu interesse para os cafés em grãos, verdes e gourmet, seja na experiência de consumo fora ou dentro de casa (ABIC, 2017). Essa experiência demanda uma série de produtos, muitas vezes específicos, que somados à variedade de grãos e torras disponíveis, multiplicam as possibilidades de bebidas obtidas. E é aí que o Design pode colaborar, uma vez que na vasta gama de produtos ligados ao preparo e consumo do café, são inúmeras oportunidades de inovação e produção com identidade e impacto econômico.

A busca por agregar valor a produtos, fortalecendo e estimulando a identidade local, é um forte impulsionador do investimento em design. Especialmente para economias emergentes, que anseiam posicionar-se de forma competitiva, o design representa um catalisador da inovação e da criação de uma imagem positiva ligada ao território, a seus produtos e serviços. (KRUCKEN-b, 2009, p. 43)

Assim, a união da força econômica e cultural do café ao potencial inovador do Design, visando o crescimento do consumo e da demanda por novas experiências de preparo, tendo foco na valorização dos produtos e produtores regionais, é campo promissor para desenvolvimento de projetos de Design em diferentes esferas. Howkins (2013, p. 39) afirma que "A criatividade por si só não tem

\footnotetext{
${ }^{1}$ ICO - International Coffee Organization. Total Production by all exporting countries 2017/18. Disponível em: $<$ http://www.ico.org/prices/po-production.pdf $>$. Acesso em 2 de julho de 2020 e ICO - International Coffee Organization. World coffee consumption 2017/18. Disponível em: <http://www.ico.org/prices/newconsumption-table.pdf $>$. Acesso em 2 de julho de 2020.

${ }^{2}$ Com base na safra de 2018 apontada em CONAB, 2018.
} 
valor econômico. Ela precisa tomar forma, ser plasmada em um produto comercializável se quiser alcançar valor comercial”.

O design pode contribuir significativamente nesse contexto [globalização], buscando formas para tornar visível à sociedade, a história por trás dos produtos. Contar a 'história do produto' significa comunicar elementos históricos, culturais e sociais associados, possibilitando ao consumidor avaliar e apreciar o produto de forma mais ampla [...]. Dessa forma, a comunicação pode contribuir para a adoção e valorização de práticas sustentáveis na produção, comercialização e consumo. (KRUCKEN-a, 2009 , p. 60)

Esse ponto de vista permite que o maior produtor da commodity café, também se torne um personagem de destaque na produção de produtos e tecnologias de consumo ligadas a este mercado, mantendo a valorização dos produtores e suas regiões já que fazem parte da mesma sociedade.

\section{Métodos}

Este estudo se apresenta como uma pesquisa descritiva por ter como objetivo traçar relações entre variáveis (GIL, 2008), neste caso específico, apresentando a evolução de objetos para preparo de um método de café por diferentes processos.

O trabalho tem como base o levantamento bibliográfico a partir de material já elaborado e disponível sobre o universo dos processos de preparo do café. Foram consultados artigos científicos, livros e websites que divulgam informações sobre: história do café, métodos e processos de preparo, produtos usados em cada método e empresas, designers e inventores dos produtos.

Dada a grande quantidade de formas de preparo do café, optou-se por delinear a pesquisa com o estudo de caso dos processos específicos para o método de infusão. O estudo de caso permite o estudo detalhado de um ou poucos objetos (GIL, 2008, p. 57), permitindo assim investigar o preparo do café e os produtos utilizados comparando-os de acordo com suas características.

Após o levantamento e o delineamento da pesquisa, analisou-se os métodos de preparo para então concluir o presente artigo.

\section{Processos e métodos de preparo}

Antes de se iniciar o preparo do café já existem variáveis que influenciarão o resultado da bebida na xícara. A começar pelo tipo de grão, arábica ou robusta e suas diferentes classificações, bem como sua origem, altitude e todas as influências edafoclimáticas. O manejo da plantação, forma da colheita, lavagem, processamento e secagem dos grãos. Até aqui, variações relacionadas à produção.

A partir da secagem o café entra na fase de beneficiamento, e os diferentes caminhos que pode seguir resultarão, cada um deles, novamente em uma nova série de variáveis de influência no sabor final. Os pontos de torra começarão a determinar algumas escolhas referentes aos métodos de preparo, e algumas vezes são tão específicos que acabam recebendo designações próprias como "italiana, francesa ou city roast" (WENDELBOE, 2018, p. 61).

O processo de torra também determina como será nossa experiência com os aromas do grão. Em outras palavras, o mesmo café pode ter sabores completamente diferentes se for torrado de maneiras diversas.

[...] É por isso que o café pode ser torrado de tantas formas, e porque cada uma delas terá seu sabor especial. (WENDELBOE, 2018, p. 56)

Considerando-se que a grande maioria dos consumidores não torra mais o próprio café, e até mesmo poucas cafeterias o fazem, é a moagem dos grãos a primeira variável ao alcance do consumidor. "Assim como outros fatores, a moagem é fundamental para a obtenção de uma boa bebida. Ela é a trituração dos grãos de café para que a bebida possa ser preparada por qualquer método escolhido" (BRESSANI, 2018, p. 137). Wendelboe (2018, p. 12) afirma que "se você quer preparar um café de qualidade, um bom moedor é artigo de primeira necessidade." 
Mesmo que outros tantos fatores venham influenciar o sabor do café a ser bebido, como a água utilizada (WENDELBOE, 2018, p. 12), a embalagem na qual foi comprado (SOUSA, CARVALHO \& PEREIRA, 2020, p. 2), a textura (CARVALHO, MOKSUNOVA \& SPENCE, 2020, p. 8), o formato (CARVALHO \& SPENCE, 2018, p. 318) e a cor das xícaras nas quais é servido (CARVALHO \& SPENCE, 2019, p. 162), e até o ambiente no qual se degusta (CARVALHO \& SPENCE, 2020, p. 7), talvez a mais importante variável de influência no sabor da bebida seja a escolha do método de preparo. Sem dúvida, é um ponto que desperta a curiosidade dos consumidores.

Deixando de lado o costume do "café bom" do "jeito certo de fazer", após a difusão do espresso, das cafeteiras elétricas, das cápsulas e do capuccino instantâneo, o consumidor se permitiu tomar café além do tradicional "torrado e moído" coado. As cafeterias oferecem uma vasta gama de métodos, e não é difícil conseguir comprar produtos para fazer cafés de formas diferentes em casa.

A nomenclatura de "métodos de preparo", amplamente utilizada nas publicações, produtos e embalagens relacionados ao café, foi empregada para classificação dos diferentes modos de se preparar a bebida. A título de uma organização que permitisse o agrupamento e a caracterização dos diferentes métodos, adotou-se o termo "processos". É preciso destacar que os processos são uma das etapas de preparo de cada método, representando assim, uma parte menor do todo. Porém, foram identificados como ponto comum que permitiu organizar de maneira lógica as várias formas de se "fazer café" e analisar os agrupamentos decorrentes desta classificação (quadro 1). Em alguns casos, um determinado método pode apresentar mais de um dos processos, sendo assim denominado "método de processos mistos".

Quadro 1 - Termos empregados para classificação dos diferentes modos de preparo do café

\begin{tabular}{|c|c|}
\hline Processos & Métodos \\
\hline Infusão & Café turco, cold brew, prensa francesa, sachê infusor, Cafe Solo*, Pressca* \\
\hline Coado & $\begin{array}{c}\text { Kyoto dripper, percolador, phin, coador de pano, cuccumella, tipo Melitta, } \\
\text { cesto, Chemex*, cafeteira elétrica, sachê coador, Hario V60*, Kalita, Kaapi }\end{array}$ \\
\hline Pressão e Vácuo & Sifão, espresso, moka, espresso em cápsulas, pressão manual \\
\hline Solúvel & Liofilizado, pulverizado, extrato, óleo de café verde, preparado de café \\
\hline Infusão + Coado & \multicolumn{2}{|c|}{ Clever* } \\
\hline Infusão + Pressão & Aeropress*, Aram*, Pipamoka*, Mini e Nanopresso* (Wacaco) \\
\hline \multicolumn{2}{|c|}{$*$ Métodos que levam o nome de um produto específico, produzido por uma determinada empresa. }
\end{tabular}

Fonte: os autores (2020)

Os processos são etapas específicas do preparo do café, que oferecem características particulares à bebida resultante. Por não serem numerosos e apresentarem distinções claras entre si, estes processos permitem uma classificação dos meios de preparo de forma coerente. Os métodos de preparo são maneiras características de se fazer o café, utilizando-se de um ou mais processos, com emprego de produtos específicos.

\section{0 processo de Infusão no preparo do café e métodos relacionados}

A infusão, se considerada pela definição de Bressani (2018, p. 215) como "forma de preparar o café que consiste em colocar o pó em contato com a água", seria um processo que caracterizaria todos os métodos de se fazer o café. Contudo, nas receitas a descrição dos métodos menciona a infusão apenas onde a água e o café permanecem em contato longo, não apenas quando ela atravessa o pó.

Assim, os métodos e produtos apresentados a seguir, são aqueles onde água e café permanecem em contato pelo tempo determinado por quem prepara a bebida. Os dois métodos de processos mistos apontados no Quadro 1, Clever e Aeropress, apresentam outros processos além da infusão cuja relevância no resultado da bebida levou a classificá-los separadamente.

Um equívoco a se evitar é imaginar que a infusão se dá apenas com o uso de água quente, uma vez que é a temperatura considerada "normal" para o café. O café extraído a frio, ou cold brew, é tão 
característico que mesmo quando a infusão é feita em produtos relacionados aqui a outros métodos, como na prensa francesa, por exemplo, a bebida resultante permanece com o nome de cold brew.

\subsection{Café turco}

O café turco, ou café grego, é preparado com o uso do Ibrik (Imagem 1), considerado a primeira cafeteira, mas não há registro específico da sua criação (provavelmente já utilizada anteriormente para outras finalidades). Sua simplicidade é uma das características que ajudou a difundir o hábito de beber café em diferentes culturas. Mesmo com o surgimento de outros métodos, ainda é um preparo comum em boa parte de países de cultura muçulmana, na Grécia e em alguns países do Leste Europeu (RAPOSEIRAS, 2014, p. 72).

O "café fervido" no Brasil, o "cowboy coffee" nos Estados Unidos e o kokekaffe na Noruega, apresentam receitas e recipientes próprios, mas seguem os princípios básicos de preparo do café turco, porém como não usam a moagem ultrafina, preveem o uso de elementos filtrantes. A presença de borra na bebida é comum nos processos americano e norueguês, enquanto no Brasil o uso do coador de pano reduz este efeito.

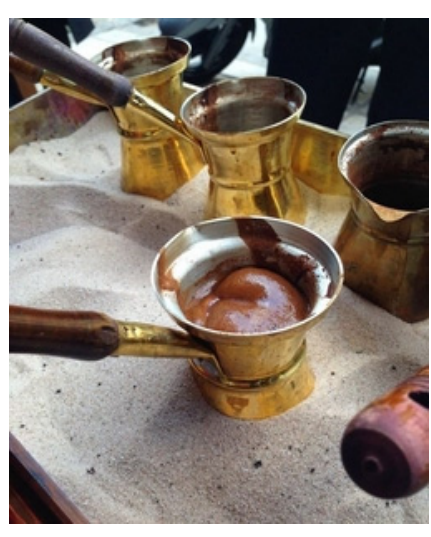

(a)

Imagem 1- Diferentes modelos de Ibrik.

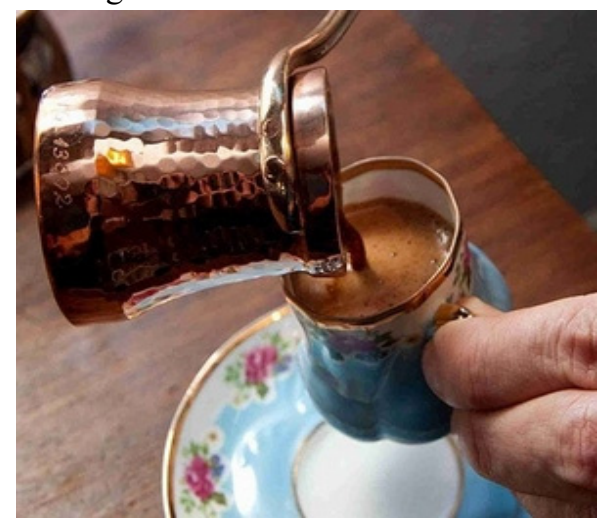

(b)

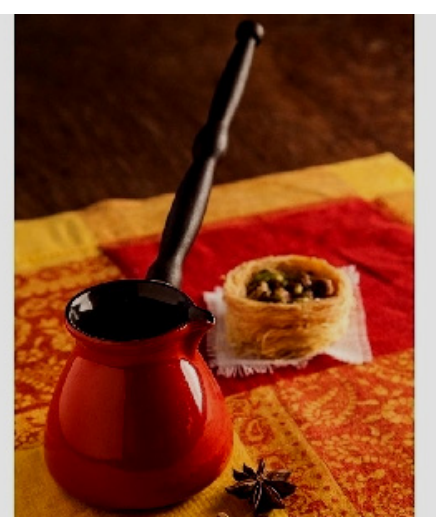

(c)

Fonte: (a) shorturl.at/wBWZ8 / (b) shorturl.at/etvwS / (c) shorturl.at/cjFR1

As características principais do café turco são o preparo de individual até 6 doses e a moagem extra-fina. A pessoa deve beber o café após a fervura, três vezes consecutivas. Depois de servido, deve-se esperar para beber, até que o pó decante. Preparado com açúcar e diferentes especiarias e até sal. Método difundido em diversos países, é tradicionalmente aquecido em recipiente com areia, mas apresenta versões elétricas conforme Imagem 2.

Imagem 2- Modelos de Ibriks elétricas.

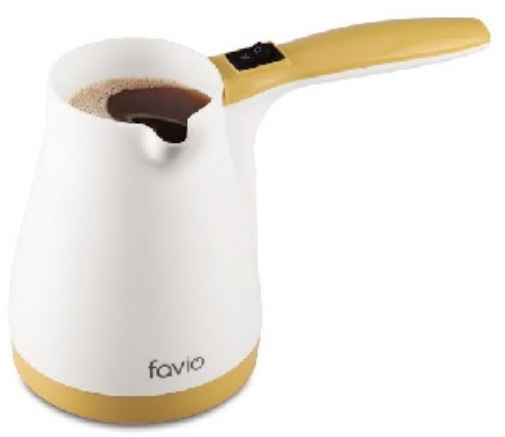

(a)

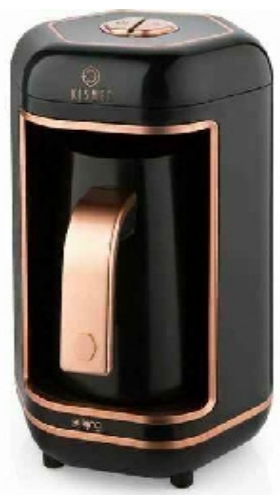

(b)

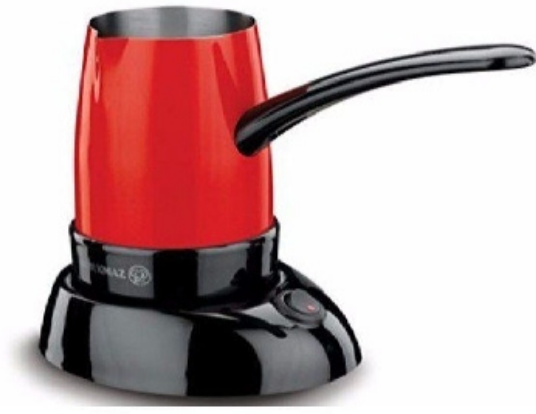

(c)

Fonte: (a) shorturl.at/oCQ14 / (b) shorturl.at/iBLWY / (c) shorturl.at/kwFKT 


\subsection{Cold brew}

O primeiro registro documental de "café frio" é da Holanda, no século XVII, quando marinheiros holandeses precisavam de uma maneira de preparar e preservar uma forma concentrada de café enquanto navegavam. Eles podem ter bebido o concentrado frio, mas é mais provável que usassem o concentrado para fazer café quente (ALTERNATIVE BREWING, 2015).

O cold brew, ou infusão a frio, não é café frio, é um café extraído a frio, o que resulta num extrato concentrado com alto teor de cafeína, usado no preparo culinário ou para o consumo diluído em água gelada, leite gelado ou no preparo de drinks com café (Imagem 3). É uma infusão longa, feita à temperatura ambiente ou, para evitar a oxidação, sob refrigeração, com posterior filtragem para remoção do pó de café (MOLDVAER, 2015, p.). O cold brew de grãos verdes é algo recente, uma vez que o transporte de café verde era impraticável até algumas décadas.

Imagem 3 - Trabalhadores de moinhos em greve bebem café gelado em piquetes em North Charlotte, em 1934.

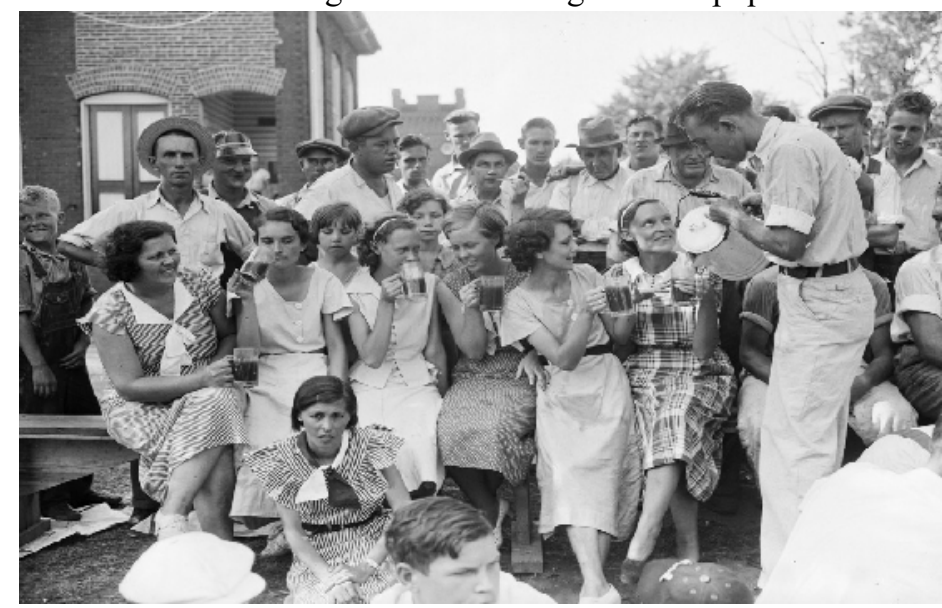

Fonte: shorturl.at/bgrF3

O preparo do cold brew pode se dar em diferentes produtos, conforme apresentado na imagem 4. É mais comum que a infusão ocorra com água gelada para evitar a oxidação do café. A temperatura da água é mantida baixa pela adição de gelo ou levando o produto para a geladeira.

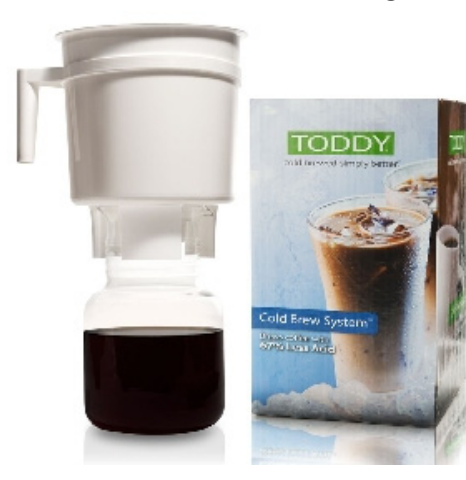

(a)

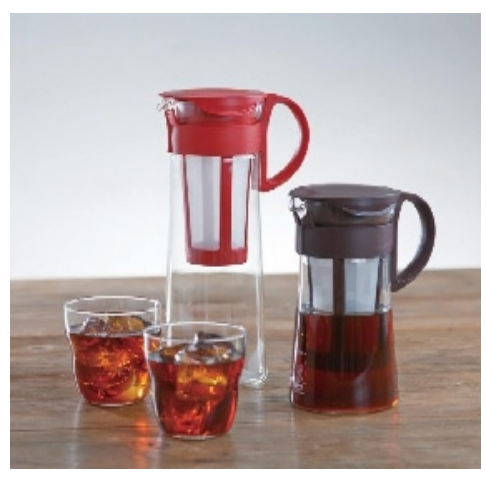

(b)

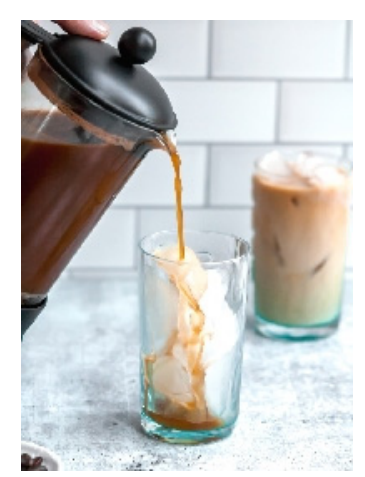

(c)

Fonte: (a) shorturl.at/amo07 / (b) shorturl.at/rDOP2 / (c) shorturl.at/bnVY9

Há produtos, como os utilizados no método Kyoto dripper, que também preparam café a frio mas foram classificados no processo de coados, uma vez que a água gelada ou em temperatura ambiente atravessa o pó muito lentamente, mas de maneira contínua.Quem prepara a bebida controla a velocidade do gotejamento (daí o nome dripper), mas não ocorre uma infusão que é interrompida ao final do processo. 


\subsection{Prensa francesa}

Registros indicam que a cafeteira francesa surgiu por volta de 1852, na França, pelas mãos de Mayer e Delforge (imagem 5). Na Itália, por sua vez, o designer Attilio Calimani registrou, em 1929, uma nova versão do produto. Entretanto, até que ela alcançasse o formato e as funcionalidades atuais, outros personagens também tiveram decisiva participação nesse processo como Bruno Cassoll, em 1935, e Faliero Bondanini, em 1958 (SOLANO, 2015) que difundiu o produto na França na década de 1960 sob o nome Chambord.

Imagem 5 - Patente de registro de Mayer e Delforge.

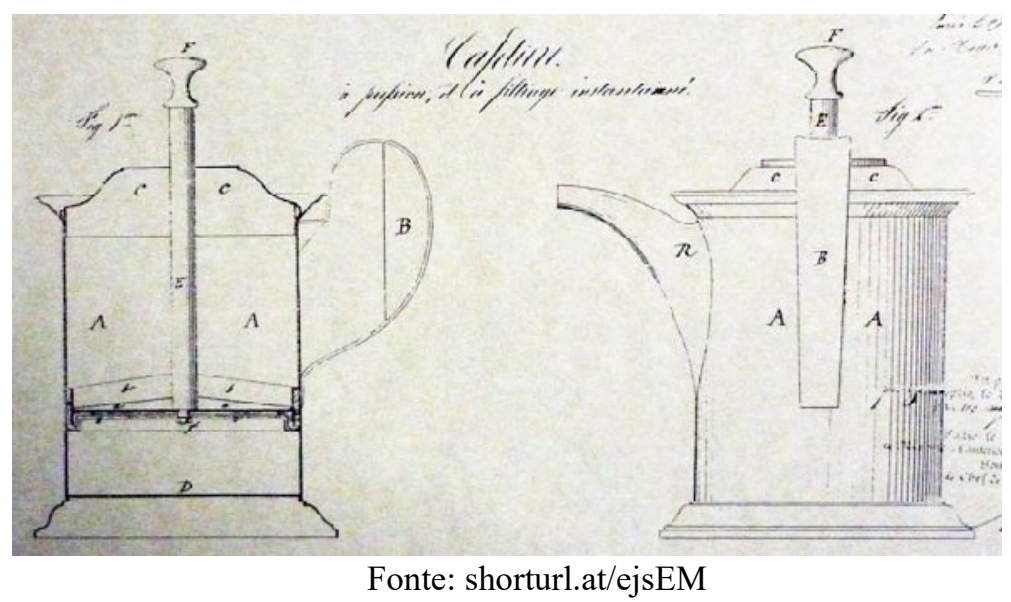

É também conhecida como Cafetière à Piston, Coffee Plunger, French Press, Prensa Francesa, Press Pot ou Cafetiere. É um método complexo de preparo do café pois variações de moagem, dosagem, temperatura da água, tempo de infusão e velocidade de extração resultam em uma vasta gama de resultados, o que representa sua vantagem e desvantagem simultaneamente.

As cafeteiras são produzidas por empresas diversas, o que resulta no uso de diferentes materiais, porém o corpo de vidro que permite a visualização do líquido em seu interior é uma caraterística em comum, mesmo havendo modelos em materiais totalmente opacos (imagem 6).

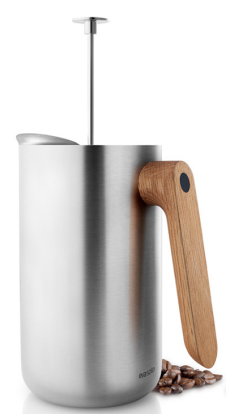

(a) Imagem 6 - Diferentes modelos de prensa francesa.

Fonte: (a) shorturl.at/iqxUV / (b) shorturl.at/sBIW7 / (c) shorturl.at/hjEM3 / (d) shorturl.at/jlmJ4

É considerada uma das maneiras mais charmosas de fazer café, permitindo servir várias pessoas e manter a qualidade da bebida (RAPOSEIRAS, 2014, p. 73).

\subsection{Sachê infusor}

Não foram encontrados registros das primeiras apresentações do café em sachê infusor, mas provavelmente ocorreram muito próximo da criação dos sachês de chá, dada a difusão do hábito de se 
beber café, que antecedeu o hábito do consumo de chá no ocidente, e pela similaridade com o processo de infusão das duas bebidas.

"Foi nos Estados Unidos [...] que inventaram essa maneira econômica e mais fácil de fazer a infusão. A história mais conhecida credita o importador de chá Thomas Sullivan como o inventor do popular saquinho em 1908”. Porém, o saquinho de chá já havia sido inventado sete anos antes disso pelas americanas Roberta C. Lawson e Mary Molaren, que registraram em 1901 a patente (imagem 7) de um sachê impressionantemente parecido com os usados hoje em dia (STONE, 2015).

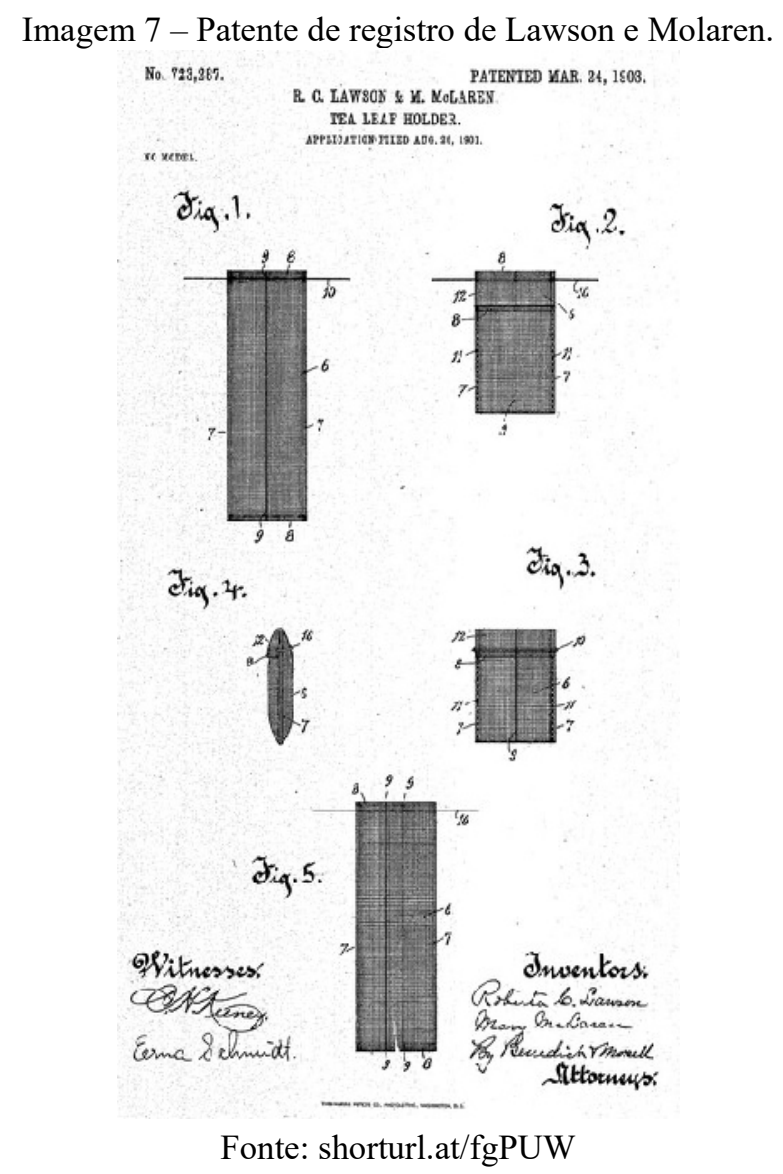

Nesse mesmo período, 1901, haviam as primeiras experiências com o café solúvel (BASTOS, 2008, p. 96), com sabor igualmente inferior, porém mais forte e prático do que o café de sachê. O café instantâneo acabou superando os "saquinhos", que ficaram mais relacionados ao chá.

O sachê infusor de café apresenta resultado desagradável, sendo mal avaliado por todos os especialistas, por isso o método não chega a ser citado na maioria das publicações. Por ficar contido no sachê, o pó de café não é devidamente espalhado na água quente, assim não libera todo seu sabor, resultando em uma bebida fraca, sem perfume e pouco apreciada. Mesmo com a conveniência de não ter que lidar com o pó, não supera sua percepção negativa geral.

Imagem 8 - Café em sachê de diferentes marcas.

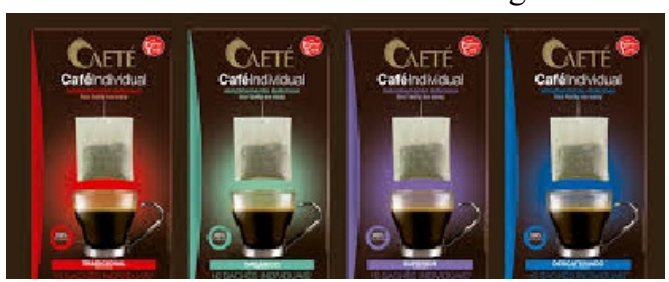

(a)

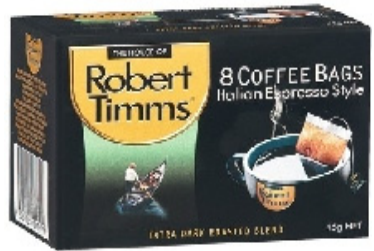

(b)

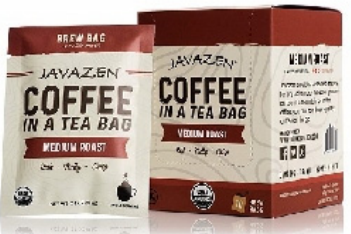

(c)

Fonte: (a) shorturl.at/bM148 / (b) shorturl.at/aeWX9 / (c) shorturl.at/kBI69 
De forma geral, as empresas que comercializam este tipo de produto, produzem sachês similares, sendo a maior variação de design dedicada às embalagens. Mesmo que ainda seja possível encontrar marcas que disponibilizam este método conforme imagem 8, o que deve cair em desuso com a difusão do sachê coador, produto criado em 1990 e que apresenta uma bebida muito bem aceita.

\subsection{Cafe Solo}

Cafeteira lançada em 2003, fartamente premiada em concursos de design e muito bem avaliada por especialistas, a Cafe Solo (grafada sem acento no "é") foi desenvolvida pelo escritório Tools Design, dos designers Claus Jensen e Henrik Holbaek (imagem 9) para a empresa Eva Denmark (PRINCE, 2014).

\section{Imagem 9 - Claus Jensen (a esquerda) e Henrik Holbaek, criadores da Cafe Solo.}

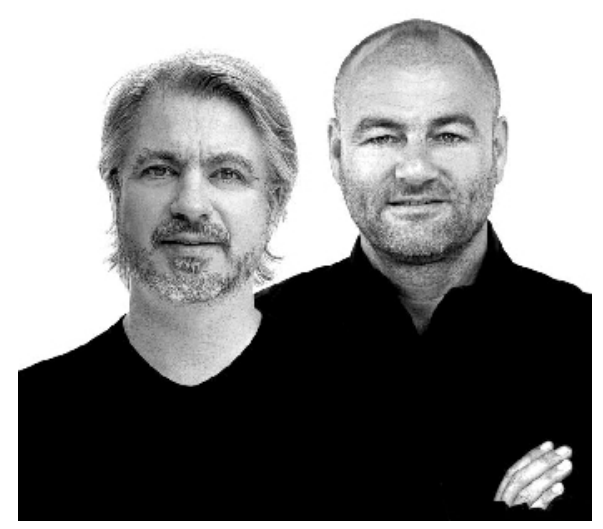

Fonte: shorturl.at/fgPUW

Similar a uma prensa francesa, porém sem a prensa, a Cafe Solo, tem grande apelo estético (imagem 10) com sua capa de neoprene com zíper. Funcionalmente seu diferencial é a tampa com filtro metálico acoplado, que filtra o café ao servi-lo, após a infusão. Por não contar com a força da pressão presente na prensa francesa, a moagem correta dos grãos é fundamental para que não dificultem a passagem do café pelo filtro.

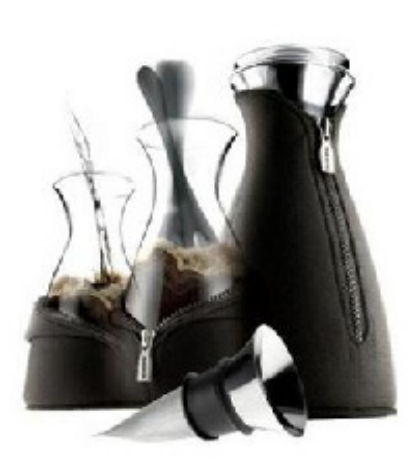

(a)

\section{Imagem 10 - Cafeteira Cafe Solo.}

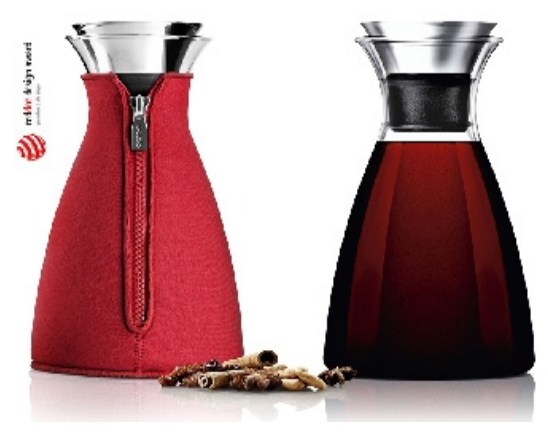

(b)

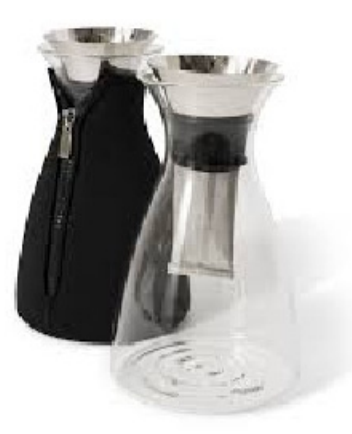

(c)

Fonte: (a) shorturl.at/jszHO / (b) shorturl.at/ikmJT / (c) shorturl.at/evO58

Assim como a prensa francesa, e outros métodos, a Cafe Solo também pode ser usada para o preparo de cold brew. 


\subsection{Pressca}

É basicamente uma prensa francesa adaptada para consumo na própria cafeteira, o que permite locomoção e facilidade de preparo fora de casa. Apresenta ótimo isolamento térmico e resistência mecânica, o que a destaca das prensas francesas tradicionais em vidro, geralmente muito frágeis.

Lançada comercialmente em 2016 (SANTOS, 2016), é um produto brasileiro desenvolvido pelo gaúcho Gerson Prates Amaro (imagem 11).

Imagem 11 - Gerson Prates Amaro, criador da Pressca.

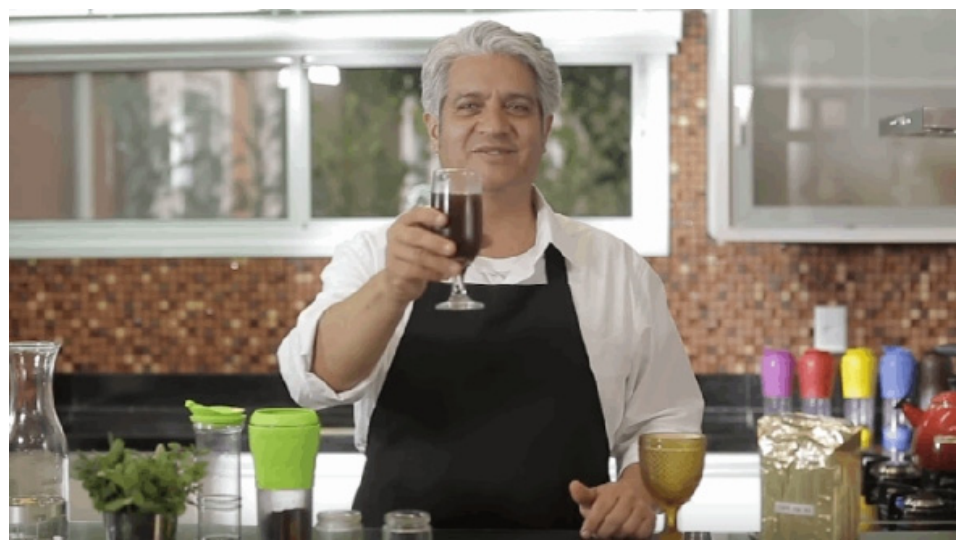

Fonte: shorturl.at//n038

Com grande apelo comercial, o preço, as cores variadas (imagem 12) e a resistência do produto, lhe garantiram abertura no mercado brasileiro e internacional. Por ser um lançamento recente, a Pressca ainda não aparece nas publicações sobre café, mas está amplamente divulgada nos canais eletrônicos sobre a bebida.

Imagem 12 - Cafeteira Pressca.

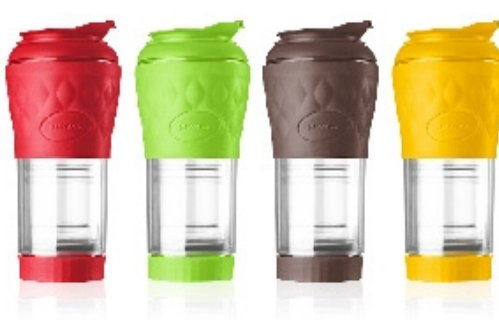

(a)

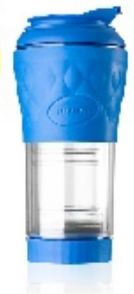

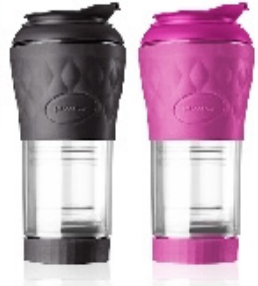

Fonte: (a) shorturl.at/ksKX6 / (b) shorturl.at/1BIVW

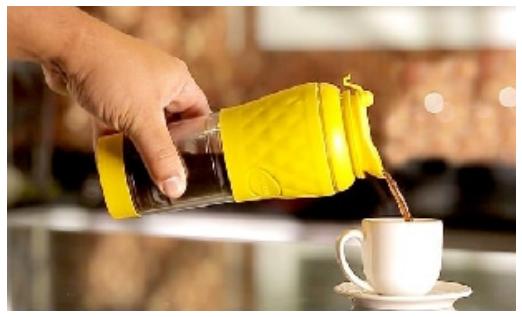

(b)

A motivação para criar a Pressca surgiu da experiência anterior de Gerson, com as prensas francesas, "Eu tive uma experiência há muitos anos atrás quando descobri as prensas francesas. Eu trazia isso para o Brasil, pois era muito difícil achar aqui. Eu as colocava na mala com o maior cuidado, pois eram frágeis.” (SANTOS, 2016). Depois da boa aceitação da cafeteira, a marca Pressca já lançou um espumador manual de leite e uma balança dosadora manual, ambos produtos para o mercado de café. A Pressca é um dos, ainda raros, exemplos de produtos desenvolvidos no Brasil para preparo do café.

\section{Conclusões: evolução sem extinção}

Os diferentes métodos para preparo do café compartilham alguns processos, porém cada uma das diversas variáveis que resultam na bebida tão apreciada em todo o mundo, permite que uma situação inusitada aconteça. De maneira geral, é comum que os produtos descrevam uma evolução onde a cada inovação, seja de materiais, de tecnologia ou mesmo de interação com o usuário ou outros produtos, 
leve à criação de uma nova solução estético-formal que acaba por extinguir o objeto original. Esta extinção se dá pela oferta de um novo produto que oferece o mesmo resultado, porém, com melhor desempenho.

É possível que por apelo emocional, tecnologias anteriores sobrevivam, mantendo-se no mercado pela existência dos consumidores que se acostumaram e afeiçoaram ao produto "anterior", ou por ondas de consumo "retrô". Mas o modelo de produção capitalista consolidou o enfraquecimento, ou completo esquecimento, desses laços com a maioria dos bens de consumo, incentivando os consumidores a substituir constantemente seus produtos pelas versões mais novas e atualizadas.

Já no mercado de café, cada inovação incorporada ao processo de preparo resulta numa bebida diferente. Detalhes simples, materiais novos, inovações radicais, não importa a mudança, o resultado na xícara é outro. Isso levou inicialmente à adoção de métodos e produtos específicos por cada cultura. Grandes consumidores como os italianos, têm preferências diferentes em relação ao ponto de torra e moagem, chegando a produtos como a moka (cafeteira italiana), a cuccumella (cafeteira napolitana) e as máquinas de expresso, onde cada um usa processos diversos e obtêm cafés de variados sobres e intensidades.

Mesmo quando fazemos um recorte por processo, escolhendo a infusão para analisar os métodos de preparo, observamos que ainda hoje a primeira cafeteira usada pelos otomanos está em uso corrente em vários países do mundo. $\mathrm{O}$ que houve com o advento do hábito de experimentar diferentes processos, métodos, grãos e combinações do café, movimento conhecido como Terceira Onda do café, foi que muitos apreciadores da bebida se abriram às experiências proporcionadas por toda essas variáveis. Assim, é comum encontrar nas cafeterias, e nas casas dos consumidores mais entusiasmados, além das tradicionais máquinas de café expresso, também o Ibrik, sachê coador, prensa francesa, Aeropress, Pressca e outros. Produtos criados desde o século XVII que convivem, não como decoração mas em pleno uso, com os últimos lançamentos da contemporaneidade.

A Pressca foi o único produto brasileiro encontrado relacionado ao processo de infusão, compondo assim o pequeno grupo de produtos de preparo de café, independentemente do método, desenvolvidos em nosso país. Há inúmeras empresas que produzem, ou reproduzem, produtos como prensas francesas, mokas e Ibriks, mas mesmo entre essas é difícil encontrar alguma inovação proposta pela indústria nacional. O sucesso da Pressca e da Aram, cafeteira manual de espresso, destacam o potencial brasileiro para propor novos produtos, mesmo que no país, o incentivo ao mercado do café ainda seja entendido apenas por ações ligadas à produção do grão ou ao consumo em larga escala. Mas com a ascensão do café especial, muitos olhares e investimentos tem se voltado para a cadeia de consumo de maneira mais ampla, possibilitando inovações ligadas às embalagens, produtos de preparo e também de consumo.

\section{Nonlinear evolution of coffee products: brewing methods}

Abstract: This article presents coffee as a relevant product in the world consumer market, with a highlighted production in Minas Gerais. Based on a bibliographic research, this work aims to present how the products used in the preparation of coffee coexist over time, not following a pattern of linear evolution in which a new product replaces its predecessor. In the case study, the infusion process and six different related methods are presented, each with specific preparation devices, being an open field for innovation through design, still poorly explored in Brazil. It is observed that in the analyzed segment, innovations and inventions, in general, do not make old products useless, since the ways of consuming coffee are varied in such a way that any change in processes or small changes in products provide new results, and so the new products end up adding to the traditional ones, and not replacing them.

Keywords: Products, coffee, design, innovation 


\section{Referências bibliográficas}

ABIC - Associação Brasileira da Indústria de Café. Tendências do mercado de cafés em 2017. Disponível em: <http://abic.com.br/src/uploads/2018/05/2017.pdf>. Acesso em 30 de abr. 2020.

ALTERNATIVE BREWING. A brief history of cold brew coffee. Disponível em $<$ https://alternativebrewing.com.au/brief-history-cold-brew-coffee/>. Acesso em 02 de agosto de 2020.

BASTOS, Giuliana. Café: com suas receitas: dicionário gastronômico. São Paulo: Gaia - Editora Boccato, 2008.

BRESSANI, Edgard. Guia do Barista: da origem do café ao espresso perfeito. São Paulo: Café Editora, 2018.

CARVALHO, F. M.; SPENCE, C. The shape of cup influences aroma, taste, and hedonic judgements of specialty coffee. In: Food Quality and Preference. Volume 68, Setembro de 2018, páginas 315321.

CARVALHO, F. M.; SPENCE, C. Cup colour influences consumers'expectations and experience on tasting specialty coffee. Food Quality and Preference. Volume 75, Julho de 2019, páginas 157169.

CARVALHO, F. M.; SPENCE, C. The coffee drinking experience: Product extrinsic (atmospheric) influences on taste and choice. Food Quality and Preference. Volume 80, Março de 2020, Artigo 103802.

CARVALHO, F. M.; MOKSUNOVA, V.; SPENCE, C. Cup texture influences taste and tactile judgments in the evaluation of specialty coffee. Food Quality and Preference. Volume 81, Abril de 2020, Artigo 103841.

CONAB - Companhia Nacional de Abastecimento. ISSN 2318-7913. Acomp. safra brasileira de café, v. 5- Safra 2018, n. 4 - Quarto levantamento, Brasília, p. 1-84, dezembro de 2018. Disponível em: <https://www.conab.gov.br/component/k2/item/download/24571_ eec1a3f8fdc30883717 a497a09f7d159>. Acesso em: 29 de maio 2020.

FARINACCIO, Rafael. De onde vieram os populares saquinhos de chá? In: Megacurioso, 30/04/2015. Disponível em <https://www.megacurioso.com.br/cultura/70077-de-onde-vieram-ospopulares-saquinhos-de-cha.htm>. Acesso em 29 de julho de 2020.

GIL, Antônio Carlos. Métodos e técnicas de pesquisa social. São Paulo: Atlas, 2008.

HERSZKOWICZ, Nathan. O futuro. In: ANDREOTTI, Carlos A. (Org.). Chefs: Café. São Paulo: Melhoramentos, 2014.

HOWKINS, John. Economia criativa: como ganhar dinheiro com ideias criativas. São Paulo: M.Books do Brasil, 2013.

ICO - International Coffee Organization. Resenha dos temas suscitados na $4^{\text {a }}$ Conferência Mundial do Café. Londres, Reino Unido, 27/05/2016. Disponível em: <http://www.ico.org/documents/cy2015-16/icc-117-5e-report-4th-wcc.pdf>. Acesso em 29 de maio 2020.

KRUCKEN (a), Lia. A comunicação da sustentabilidade de produtos e serviços. In: DE MORAES, Dijon, KRUCKEN, Lia (org.). Cadernos de estudos avançados em design: Sustentabilidade I. EdUEMG, 2009. p. 59- 68.

KRUCKEN (b), Lia. Design e território: valorização de identidade e produtos locais. São Paulo: Studio Nobel: 2009.

MAPA - Ministério da Agricultura, Pecuária e Abastecimento. Café no Brasil. Brasília, 18/09/2018. Disponível em: <http://www.agricultura.gov.br/assuntos/politica-agricola/ cafe/cafeiculturabrasileira>. Acesso em: 28 de julho de 2020.

MOLDVAER, Anette. 0 Livro do Café: História, espécies e variedades, indicadores de qualidade, técnicas de barista, cafés pelo mundo, equipamento e receitas. São Paulo: Publifolha, 2015. 
OLIVEIRA, José Tadeu de. Comportamento do consumidor exige qualidade e sabores diferenciados. Revista Attalea Agronegócios. Franca, 19 de março de 2019. Disponível em: $<$ https://revistadeagronegocios.com.br/jose-tadeu-de-oliveira-mudanca-no-comportamento-doconsumidor-exige-do-produtor-qualidade-e-sabores-diferenciados/>. Acesso em: 28 abr. 2019.

PRINCE, Mark. Eva Solo Cafe Solo. In: Coffee Geek / Product Review, 03/02/2014. Disponível em <http://coffeegeek.com/proreviews/quickshot/evasolocafesolo/details>. Acesso em 28 de julho de 2020.

RAPOSEIRAS, Isabela. O futuro. In: ANDREOTTI, Carlos A. (Org.). Chefs: Café. São Paulo: Melhoramentos, 2014.

SANTOS, Felipe. Batemos um papo com Gerson Prates Amaro, o criador da Pressca. In: Grão Gourmet, 14/12/2016. Disponível em <https://www.graogourmet.com/blog/batemos-um-papo-comgerson-prates-amaro-o-criador-da-pressca/>. Acesso em 27 de julho de 2020.

SOLANO, Fabiola. French Press: The History \& Brewing Guide. In: Perfect Daily Grind, 10/05/2015. Disponível em: <https://perfectdailygrind.com/2015/05/french-press-the-history-brewing-guide/>. Acesso em 30 de julho 2020.

SOUSA, Maísa M.M. de; CARVALHO, Fabiana M.; PEREIRA, Rosemary G.F.A. Colour and shape of design elements of the packaging labels influence consumer expectations and hedonic judgments of specialty coffee. In: Food Quality and Preference. Volume 83, Julho de 2020, Artigo 103902.

STONE, Sarah. How the Tea Bag Was Invented. In: Gizmodo, 27/04/2015. Disponível em <https://gizmodo.com/how-the-tea-bag-was-invented-1700351584>. Acesso em 29 de julho de 2020.

WENDELBOE, Tim. Coffee com Tim Wendelboe. São Paulo: Café Editora, 2018. 